\section{Estudo \\ Ecidebate}

em Testão

Plamejamento
Revista Estudo \& Debate, Lajeado, v. 24, n. 2, 2017. ISSN 1983-036X

DOI: http://dx.doi.org/10.22410/issn.1983-036X.v24i2a2017.1284

\title{
ANÁLISE DA RELAÇÃO ENTRE INOVAÇÃO, MERCADO ACIONÁRIO E CRESCIMENTO ECONÔMICO NOS PAÍSES DO BRICS
}

\author{
Gelson Eduardo Dalle Nogare ${ }^{1}$, Marcos Lucas de Oliveira² ${ }^{2}$ Jéferson Réus da Silva Schulz ${ }^{3}$, \\ Janis Elisa Ruppenthal ${ }^{4}$
}

\begin{abstract}
Resumo: A problemática da pesquisa consiste em discutir se o mercado de açôes pode ser um preditor da evolução do crescimento econômico e da inovação tecnológica e servir como um indicador econômico, para o caso dos países membros do BRICS. O objetivo desse estudo é analisar o comportamento e a relação do mercado acionário com a evolução macroeconômica, tendo como base o desenvolvimento tecnológico, através das variáveis que influenciam esses índices para o Brasil, Rússia, Índia, China e África do Sul - BRICS. Foi estipulado como referência para o quesito inovação o indicador fornecido pelo The Global Innovation Index, o GII, para o quesito crescimento econômico, o PIB real, e, para o quesito mercado de capitais, o principal índice de açôes da bolsa de valores de cada país. Para analisar e relacionar essas variáveis se fez uso do coeficiente de correlação. Os resultados sugerem a rejeição da hipótese de estudo de maneira sistemática, visto que o desempenho do mercado de capitais náo pode servir de indicador econômico, uma vez que náo são apresentadas evidências de que seu desempenho esteja relacionado com o desempenho da economia real e da inovação tecnológica.
\end{abstract}

Palavras-chave: Inovação. Crescimento econômico. Mercado acionário. BRICS. The Global Innovation Index.

\section{ANALYSIS OF RELATIONSHIP BETWEEN INNOVATION, STOCK MARKET AND ECONOMIC GROWTH IN BRICS COUNTRIES}

\begin{abstract}
The research problem is to discuss whether the stock market can be a predictor of the evolution of economic growth and technological innovation and serve as an economic indicator for the BRICS member countries. The aim of this study is to analyze the behavior and the relationship of the stock market with macroeconomic developments, based on technology development, through the variables that influence these indices for Brazil, Russia, India, China and South Africa - BRICS. It was set as a reference for question
\end{abstract}

1 Mestre em Engenharia de Produçáo pelo Programa de Pós-Graduação em Engenharia de Produção da UFSM.

2 Mestrando em Engenharia de Produção pelo Programa de Pós-Graduação em Engenharia de Produção da UFSM.

3 Mestrando em Engenharia de Produção pelo Programa de Pós-Graduação em Engenharia de Produção da UFSM.

4 Doutora em Engenharia de Produção e professora no Programa de Pós-Graduação em Engenharia de Produção da UFSM. 
innovation indicator provided by The Global Innovation Index, the GII, for question economic growth, real GDP, and, to the capital market aspect, the main index of the stock exchange of shares of each country. To analyze and relate these variables made use of the calculation of the correlation coefficient. The results suggest the rejection of the hypothesis of the study in a systematic way, seeing that performance of the capital market cannot be an economic indicator, since not there evidence that their performance is related to the performance of the real economy and technological innovation.

Keywords: Innovation. economic growth. stock market. BRICS. The Global Innovation Index.

\section{INTRODUÇÃO}

Relacionar crescimento econômico com o desenvolvimento dos sistemas financeiros tem sido um tema controverso e suscitado debates inconclusivos ao longo dos últimos anos no meio científico. Reconhecendo-se a importância desse assunto e incorporando a inovação a essa temática, o presente estudo busca discutir se o setor financeiro precede o crescimento econômico de uma economia, ou se é o setor real que impulsiona a evolução e o desenvolvimento do setor financeiro.

Países desenvolvidos e em desenvolvimento têm dedicado atenção à relação existente entre o desenvolvimento do setor financeiro e o crescimento econômico, aliado ao papel desempenhado pela inovação nesse cenário. De acordo com Ribeiro e Porto (2015), através de políticas públicas direcionadas ao fomento à inovação, concomitantemente à aplicação de investimentos vultosos de recursos, o crescimento econômico de longo prazo e o bem-estar social são viabilizados pela adição de inovação enquanto elemento gerador de competitividade econômica.

Estudos que comprovam a ligação dinâmica entre o desenvolvimento financeiro baseado nos bancos, o desenvolvimento do mercado de açóes e o crescimento econômico, são pouco explorados pela literatura especializada. Alguns estudos procuram examinar empiricamente a complementaridade entre o desenvolvimento financeiro baseado em bancos e o desenvolvimento do mercado de açóes no reforço ao crescimento econômico. Além disso, a maioria desses estudos concentra-se principalmente em países da Ásia e da África (ODHIAMBO, 2008; MITCHENER; OHNUKI, 2009; LI, 2012; MOHD, 2012; FASANYA; ONAKOYA; OFOEGBU, 2013; ODHIAMBO, 2014; NGAREA; NYAMONGOB; MISATI, 2014; AHMED; MMOLAINYANE, 2014; ODHIAMBO, 2014).

Mankiw (2011) enfatiza que tal relação torna-se ainda mais dispersa quando se procura analisar a relação e o papel da inovação como mecanismo propulsor do desempenho do mercado acionário e, consequentemente, da economia real. Conforme o referido autor, os economistas consideram que essa relação poderia residir na hipótese de que uma diminuição nos preços das açóes seria capaz de refletir em notícias negativas no que concerne ao progresso tecnológico e ao crescimento econômico de longo prazo. $\mathrm{O}$ autor sustenta que a consequência disso reflete-se no nível natural de produção e, por conseguinte, na oferta agregada de bens e serviços, que tenderá a crescer mais lentamente no futuro do que se esperava anteriormente.

Essas relações entre o mercado de ações, a economia real e as variações do nível tecnológico, não podem passar despercebidas pelos formuladores de políticas econômicas. 
Isso porque os dados sobre o mercado acionário antecipam muitas vezes variaçóes no Produto Interno Bruto (PIB) real, visto que os dados sobre as açôes estão disponíveis mais rapidamente do que os dados relativos ao PIB.

Com o advento da globalização da economia mundial e devido às recentes transformaçóes ocorridas no cenário econômico mundial, as economias emergentes passaram a ocupar posições de destaque em âmbito internacional. Com efeito, os países em desenvolvimento têm apresentado crescente importância na economia mundial, atraindo parcelas importantes do investimento e da produção mundiais (SAYAD; SILBER, 2005).

Tal evidência se deve ao fato de esses países apresentarem expressivos índices de crescimento e figurarem como importantes polos políticos, econômicos e regionais. São também responsáveis por parte significativa do dinamismo econômico mundial dos últimos anos, uma vez que passaram a ampliar seus espaços de atuação política em instituiçóes e fóruns internacionais, como é o caso do Brasil, da Rússia, da Índia, da China e da África do Sul (BRICS). A relevância em estudar os países membros do BRICS e os processos econômicos particulares dessas economias, justifica-se por ser o BRICS uma novidade tanto em relação à política externa brasileira quanto em relação às alianças Sul-Sul no que tange à redefinição da ordem internacional (CARMO, 2011).

A problemática da pesquisa reside em discutir, em linhas gerais, se o mercado de açóes pode ser considerado um preditor da evolução do crescimento econômico e da inovação tecnológica e ainda servir como um indicador econômico para o caso dos países membros do BRICS. O objetivo desse estudo fundamenta-se em analisar o comportamento e a relação do mercado acionário com a evolução macroeconômica, tendo como base o desenvolvimento tecnológico nos países que constituem o BRICS. Para tanto, testa-se a hipótese de que uma diminuição nos preços das açóes pode estar refletindo más notícias em relação ao progresso tecnológico e ao crescimento econômico de longo prazo.

\section{REFERENCIAL TEÓRICO}

\subsection{Inovação tecnológica}

Ainovação tecnológica nãoé um fenômeno recente, sendo inerente ao desenvolvimento humano e dotada da capacidade de mudar o comportamento das pessoas, os métodos de trabalho e conduzir ao crescimento econômico. No último século, a maioria das naçóes logrou um crescimento sustentado em termos de PIB real e PIB per capita que, apesar de retrocessos em algumas décadas, apresenta como tendência generalizada uma ascensão econômica no longo prazo (SACHS; LARRAIN, 2000).

Maddison (1983), historiador e teórico do crescimento econômico, realizou um estudo em que analisou a evolução da população mundial e do PIB per capita em um longo período de tempo, desde o ano 500 d.c. até o ano 1980, dividindo-o em quatro épocas distintas: (i) agricultura (500-1500); (ii) agricultura desenvolvida (1500-1700); (iii) agricultura mercantilista (1700-1820); e (iv) capitalismo (1820-1980). Em sua pesquisa, o autor conclui que nos séculos iniciais não houve um aumento considerável entre o crescimento da população e o crescimento do PIB per capita. No entanto, um verdadeiro 
salto foi observado no início da fase do capitalismo moderno (1820-1980), quando o crescimento do PIB per capita aumentou aproximadamente $1,60 \%$ ao ano e o crescimento populacional mais que duplicou.

Kuznets (1966), autor de estudos quantitativos do crescimento econômico moderno, ressalta que sua origem remonta à Revolução Industrial, mais especificadamente entre 1780 e 1820 na Inglaterra, 1810 e 1860 nos Estados Unidos e 1820 e 1870 na Alemanha. O autor enfatiza que nessas naçóes o surgimento do crescimento econômico coincidiu com o surgimento do capitalismo como sistema econômico dominante. Em seu estudo, conclui que o crescimento econômico desses países ocorreu simultaneamente ao crescimento populacional e ao crescimento da renda per capita, acompanhados por avanços tecnológicos significativos.

Para Tigre (2006), é inegável a contribuição da Revolução Industrial na história econômica do ocidente, considerando seu impacto sobre o crescimento da produtividade. Desde o início do século XVIII observam-se sucessivas ondas de inovação obtidas pela implementação de novas máquinas e equipamentos, pela introdução de novas formas de organização da produção e pelo desenvolvimento de novas fontes de materiais e energia.

Conforme o exposto, é possível considerar que a difusão do conhecimento constitui uma etapa fundamental para estimular o crescimento econômico. Primeiramente, a inovação torna os produtos mais competitivos, permitindo que as empresas os introduzam em um maior número de mercados e possibilitando a abertura de novos empreendimentos. Em segundo lugar, abordagens teóricas empíricas reforçam a importância dos processos de inovação por fatores intrínsecos, que incentivam sua introdução de forma disseminada nas empresas (SCHUMPETER, 1951; GOLDSMITH, 1969; LUCAS, 1972; ROMER, 1990; MANKIW, 2011; GALINDO; PICAZO, 2013).

Porter (1999) salienta que, na medida em que os fundamentos da competição se deslocam para a criação e assimilação de conhecimento, os países se tornam mais competitivos. $\mathrm{O}$ autor sustenta que a prosperidade nacional não é algo herdado dos recursos naturais de um país, de sua moeda, de suas taxas de juros ou da sua força de trabalho, pelo contrário, o que torna um país próspero é um processo altamente focalizado em seu nível nacional de produtividade, sedimentado em seus valores, em sua cultura, em suas instituiçóes e em sua estrutura econômica. Sua conclusão foi embasada em quatro anos de estudo sobre dez importantes economias globais: Dinamarca, Alemanha, Itália, Japão, Coréia, Singapura, Suécia, Suíça, Reino Unido e Estados Unidos.

Schumpeter (1951) introduziu o termo "destruição criadora", sugerindo que a força propulsora do processo de crescimento econômico viria através da figura do empreendedor, com uma ideia para um novo produto, um modo diferente de se fabricar um antigo produto ou alguma outra inovaçáo. Sua teoria baseia-se na premissa de que ao entrar no mercado, a empresa do empreendedor deterá algum poder de monopólio sobre sua inovação. A entrada da nova empresa é positiva para o consumidor que passará a ter uma maior gama de opções, no entanto, constituirá um fator negativo para outras empresas pela dificuldade de concorrer com o novo entrante. Caso uma organização apresente uma inovação radical e perturbadora, implicará na saída dos concorrentes do mercado, caracterizando assim um processo permanente de constante renovação, visto que a empresa do novo empreendedor 
desfrutará de um elevado patamar de lucratividade até que seu produto seja superado por outro empreendedor com a geraçáo de uma ideia nova.

Mankiw (2011) enfatiza que o crescimento econômico de longo prazo é o único determinante da prosperidade econômica de um país e que padróes de vida elevados são provenientes do crescimento sustentado da produtividade, o que exige um constante aprimoramento da economia como um todo. $\mathrm{O}$ autor reforça que políticas públicas que fazem crescer o nível de progresso tecnológico de uma nação devem ser o objetivo mais importante a ser seguido.

\subsection{Teorias do crescimento econômico}

Há, na literatura especializada, diversos estudos na esfera do desenvolvimento econômico. Cita-se, como pioneiro, Schumpeter (1951) e sua teoria do desenvolvimento econômico, que sustenta que o crescimento econômico deriva de uma maior eficiência na alocação dos recursos de uma economia.

Mais tarde, outros estudos surgiram e ganharam destaque nessa área através de seus modelos de crescimento econômico (SOLOW, 1956; MODIGLIANI; MILLER, 1958; GOLDSMITH, 1969; HICKS, 1969; SHAW, 1973). Com efeito, posteriormente surgiram os modelos de crescimento endógeno, permitindo um maior aprofundamento na análise do desenvolvimento financeiro, mais especificadamente na relação entre o desempenho do mercado de capitais e o crescimento econômico (ROMER, 1986; LUCAS, 1988).

Romer (1986) e Lucas (1988) procuraram compreender e descrever, ao longo dos anos, qual a relaçáo de causa e efeito entre crescimento econômico e desenvolvimento financeiro, sendo desenvolvidas algumas teorias que nem sempre sustentaram as mesmas hipóteses. Shumpeter (1982), assim como outros autores, defendeu como premissa básica para o desenvolvimento de uma economia o papel essencial da inovaçáo tecnológica. Dessa forma, o autor argumenta que existe uma relação favorável entre o desenvolvimento dos mercados financeiros e o de capitais e o crescimento econômico, observando que um setor financeiro desenvolvido conduz a um aumento natural do PIB.

Com o seu modelo de crescimento exógeno, Solow (1956) defende que o crescimento econômico no longo prazo dependeria da junção dos fatores de produçáo capital e trabalho e da tecnologia para transformar capital e mão de obra em produtos. Assim, o PIB cresceria quando os fatores de produção aumentam ou quando a economia se torna mais eficiente na transformação desses insumos em um produto composto por bens e serviços.

Sob o argumento de que não é somente o papel da inovaçấo tecnológica que contribui para o crescimento econômico, Hicks (1969) sustenta que o surgimento do mercado de capitais possibilita a mobilidade de grandes recursos. Segundo o autor, isso também permite a introdução da tecnologia na produção industrial, resultando em uma acentuada expansão econômica.

Com a teoria do crescimento endógeno, Romer (1986) e Lucas (1988) defendem que o crescimento econômico é resultante de níveis mais elevados de poupança e de investimento. Ao sustentar a mesma hipótese de Romer (1986), Lucas (1988) destaca a 
necessidade de se enumerar e quantificar todas as diferentes variáveis, que não apenas as financeiras, para que um modelo econômico seja relevante.

Com efeito, se o desenvolvimento do setor financeiro for quantificado através do nível de capacidade de financiamento e do mercado acionário, os mercados financeiros antecipam o crescimento da economia. Essa percepção deve-se ao fato de o mercado acionário capitalizar as empresas e, consequentemente, evidenciar oportunidades de investimento e direcionar os recursos para os setores mais atrativos, resultando em uma "seleção natural", predispondo uma antecipação do futuro econômico (LUCAS, 1988).

Ao analisar dados de 35 países ao longo de várias décadas, Goldsmith (1969) conclui que existe uma forte relação entre o crescimento econômico e o desenvolvimento do sistema financeiro. Corroborando com a ideia de Goldsmith (1969), Shaw (1973) realizou estudo e evidenciou que países com grande crescimento econômico apresentam mercados financeiros evoluídos.

Em oposição ao descrito anteriormente, Modigliani e Miller (1958) rejeitam a hipótese de existir evidente relação entre o desenvolvimento financeiro e o crescimento econômico. Sob essa ótica, os mercados financeiros são independentes da economia e a forma como as empresas obtêm financiamento não deve ser levada em consideração.

A relação entre o desenvolvimento do mercado de açóes, o desenvolvimento do sistema financeiro e o crescimento econômico, atualmente, não tem sido amplamente investigada a partir de perspectivas teóricas e empíricas. Embora tais estudos tenham sido realizados, a análise dos resultados não demonstra evidências conclusivas sobre a efetiva relação entre desenvolvimento financeiro baseado nos bancos, crescimento econômico e desenvolvimento do mercado de açóes (ODHIAMBO, 2014).

\subsection{Desempenho do mercado acionário}

O estudo realizado por Levine e Zervos (1998) é de considerável relevância uma vez que investiga empiricamente a relação entre o desenvolvimento do mercado acionário e o crescimento econômico. Utilizando dados de séries temporais para 16 economias emergentes, o estudo avaliou o comportamento, o tamanho do mercado de açóes, a liquidez, a volatilidade e a integração internacional após a abertura econômica dos seus fluxos internacionais de capitais e dividendos. Os resultados demonstram que os mercados de açóes se tornam maiores, mais líquidos e mais voláteis após o processo de abertura internacional, mostrando-se preditores robustos do crescimento econômico e do PIB per capita no longo prazo. Essas economias apresentaram indicadores institucionais consistentes de regulação e desenvolvimento do mercado acionário, estabelecendo confiança e credibilidade aos investidores.

Zhang, Wang e Wang (2012), ao utilizarem dados em painel, analisaram a relação dinâmica entre desenvolvimento financeiro e crescimento econômico em 286 cidades chinesas durante o período de 2001 até 2006. Suas conclusôes sugerem uma associação positiva entre os tradicionais indicadores de desempenho financeiro e o crescimento econômico, contrariando as estimativas de que um setor bancário, gerido pelo Estado, como é o caso da China, dificultaria o crescimento econômico. 
Sustentando a hipótese de que o mercado acionário antecipa com relativa precisão a evolução macroeconômica de uma nação, Pilo (2012) realizou um estudo em seis países africanos: África do Sul, Egito, Quênia, Ilhas Maurícias, Marrocos e Nigéria. Utilizando os dados intertemporais disponíveis, o autor analisou a evolução do mercado acionário desses países, comparando-os com a taxa de variação do PIB e a taxa de variação do índice de desemprego. Concluiu que não foi possível estimar de forma precisa a validação ou rejeição da hipótese do trabalho, pois, considerando-se a relação entre o desempenho do mercado acionário com a performance evolutiva do PIB, a hipótese é confirmada apenas para África do Sul, Egito, Ilhas Maurícias e Quênia.

Ahmed e Mmolainyane (2014), em estudo realizado em Botswana, exploraram o impacto da integração financeira sobre o crescimento econômico no período de 1974 a 2009, não encontrando associação direta, robusta e estatisticamente significativa entre o desenvolvimento do sistema financeiro e o crescimento econômico. Contudo, os resultados sinalizam que a integração financeira é positiva e significativamente correlacionada com o desenvolvimento financeiro da economia.

Em outro estudo, Ngarea, Nyamongob e Misati (2014) analisaram o desenvolvimento do mercado de açóes e a sua contribuição para o crescimento econômico na África. Observando dados em painel, para o período de 1980 a 2010, em 36 países africanos, sendo que destes apenas 18 tem mercado de ações, os resultados demonstram que o desenvolvimento do mercado de açóes tem um efeito positivo sobre o crescimento econômico e que os países com mercados de açóes tendem a crescer mais rapidamente em comparação com aqueles que não possuem mercado de açóes.

Odhiambo (2014), com a utilização de procedimentos econométricos, analisou e testou a complementaridade do desenvolvimento bancário e do mercado de ações ao processo de crescimento econômico da África do Sul para o período de 1994 a 2011. Com a adoção de variáveis interativas, investigou o desempenho do sistema bancário e do crescimento do mercado de açóes estipulando três proxies como sendo as mais significativas para o mercado acionário: (i) capitalização do mercado de ações; (ii) valor negociado no mercado de açóes; e (iii) volume de negócios do mercado de açóes. Isso, contra a razão de uma proxie estipulada para medir o desenvolvimento financeiro baseado nos bancos e ao crédito ao setor privado.

Com a finalidade de controlar os determinantes potenciais de crescimento econômico nas regressões, foram utilizadas outras variáveis macroeconômicas como as usadas por Levine e Zervos (1998), Beck e Levine (2004), e, Shen e Lee (2006), especificamente: a inflação, a abertura de mercado, os gastos do governo e o capital humano. Os resultados do estudo de Odhiambo (2014) demonstram que a complementaridade entre o desenvolvimento bancário e o desenvolvimento do mercado de ações é fraco e sensível ao se analisar as proxies utilizadas para medir o desenvolvimento do mercado acionário.

\subsection{The Global Innovation Index (GII)}

O Índice Global de Inovação, ou The Global Innovation Index (GII), consiste em um ranking da capacidade de inovação das economias mundiais. Reconhecendo o papel 
fundamental da inovação como motor do crescimento econômico, da prosperidade e da necessidade de uma ampla visão horizontal de inovação aplicável às economias desenvolvidas e emergentes, o GII inclui indicadores que vão além das medidas tradicionais de inovaçáo, como o nível de pesquisa e desenvolvimento.

Lançado oficialmente em 2007, o GII estabeleceu-se como a principal referência entre os índices de inovação e representa uma importante ferramenta de benchmarking que visa facilitar o diálogo entre as instituições público-privadas, em que os responsáveis políticos, líderes empresariais e outros interessados, podem avaliar o progresso em uma base contínua. O GII reúne dados de mais de 30 fontes, cobrindo um largo espectro de condutores de inovação e de resultados, privilegiando dados concretos sobre avaliaçóes qualitativas.

O GII tem como objetivo alcançar a melhoria do "percurso" para um melhor entendimento da medição da inovação. Para tanto, parte da identificação de políticas focalizadas, em que as boas práticas e outras alavancas possibilitam que emerja a inovação.

O The Global Innovation Index (GII) baseia-se em dois subíndices. Um subíndice de entrada de inovação e outro subíndice de saída de inovação, cada um construído em torno de pilares fundamentais. Para o subíndice de entrada de inovação, são cinco pilares de entrada que descrevem e capturam os elementos da economia nacional, identificando as atividades inovadoras: (i) instituiçóes; (ii) capital humano e pesquisa; (iii) infraestrutura; (iv) sofisticação do mercado; e (v) sofisticação de negócios. Já para o subíndice de saída de inovação, são dois os pilares que descrevem e capturam as evidências reais de resultados da inovação: (i) saída de conhecimento e tecnologia; e (ii) saídas criativas (GII, 2015).

Cada pilar está dividido em subpilares e cada subpilar é composto por indicadores individuais (81 no total). Pontuaçóes subpilar são calculadas como a média ponderada dos indicadores individuais e pontuaçôes pilar são calculadas como a média ponderada das pontuaçôes subpilar. Quatro medidas são então calculadas: (i) o Subíndice de Entrada de Inovação, que representa a média simples das pontuaçôes dos primeiros cinco pilares; (ii) o Subíndice de Saída de Inovação, que representa a média simples dos dois últimos pilares; (iii) o GII Geral, que representa a média simples dos Subíndices de entrada e saída; e (iv) o Índice de Eficiência de Inovação, que representa a relação entre o Subíndice de Saída de Inovação e o Subíndice de Entrada de Inovação (GII, 2015).

\section{METODOLOGIA DO ESTUDO}

Para que os objetivos dessa pesquisa fossem satisfeitos, se fez uso da correlaçáo estatística como ferramenta de análise, com a utilização do programa estatístico Statistica ${ }^{\circ}$. Os dados foram coletados levando em consideração um período de cinco anos, que compreende os anos de 2010, 2011, 2012, 2013 e 2014. A síntese dos dados utilizados é apresentada no Quadro 1.

O quesito inovaçáo tem como referência o The Global Innovation Index, baseado na nota de posicionamento global de cada país em análise. Para os dados referentes ao desempenho macroeconômico, a referência é o PIB real, tendo como base os valores monetários fornecidos pela Organização para a Cooperaçáo e Desenvolvimento Econômico (OCDE), expressos em dólares americanos atualizados. E, para o mercado de capitais, 
utilizou-se o principal índice de cotação das ações da bolsa de valores dos países analisados, tendo como base o valor expresso no último dia do pregão de cada ano.

Quadro 1 - Dados compilados para análise

\begin{tabular}{|c|c|c|c|}
\hline Brasil & GII & PIB real & IBOVESPA \\
\hline 2010 & $68^{\circ}$ & $2.143 .067 .871 .760,00$ & $69.304,81$ \\
\hline 2011 & $47^{\circ}$ & $2.476 .694 .763 .271,00$ & $56.754,08$ \\
\hline 2012 & $58^{\circ}$ & $2.248 .780 .912 .396,00$ & $60.952,08$ \\
\hline 2013 & $64^{\circ}$ & $2.245 .673 .032 .354,00$ & $51.507,16$ \\
\hline 2014 & $61^{\circ}$ & 2.247.918.705.386,35 & $50.007,41$ \\
\hline Rússia & GII & PIB real & RTSI \\
\hline 2010 & $64^{\circ}$ & $1.524 .916 .112 .079,00$ & $1.770,28$ \\
\hline 2011 & $56^{\circ}$ & $1.904 .793 .021 .649,00$ & $1.381,87$ \\
\hline 2012 & $51^{\circ}$ & $2.017 .470 .930 .421,00$ & $1.526,98$ \\
\hline 2013 & $62^{\circ}$ & $2.096 .777 .030 .571,00$ & $1.442,73$ \\
\hline 2014 & $49^{\circ}$ & $2.109 .357 .692 .754,43$ & 790,71 \\
\hline Índia & GII & PIB real & S\&P BSE SENSEX \\
\hline 2010 & $56^{\circ}$ & $1.708 .458 .876 .830,00$ & $20.509,09$ \\
\hline 2011 & $62^{\circ}$ & $1.843 .016 .600 .065,00$ & $15.454,92$ \\
\hline 2012 & $64^{\circ}$ & $1.835 .818 .207 .215,00$ & $19.426,71$ \\
\hline 2013 & $66^{\circ}$ & $1.875 .141 .481 .991,00$ & $21.170,68$ \\
\hline 2014 & $76^{\circ}$ & $1.980 .149 .404 .982,50$ & $27.499,42$ \\
\hline China & GII & PIB real & SEE COMPOSITE \\
\hline 2010 & $43^{\circ}$ & $5.930 .502 .270 .313,00$ & $2.808,08$ \\
\hline 2011 & $29^{\circ}$ & $7.321 .891 .954 .608,00$ & $2.199,42$ \\
\hline 2012 & $34^{\circ}$ & $8.229 .490 .030 .100,00$ & $2.269,13$ \\
\hline 2013 & $35^{\circ}$ & $9.240 .270 .452 .047,00$ & $2.115,98$ \\
\hline 2014 & $29^{\circ}$ & $9.924 .050 .465 .498,48$ & $3.234,68$ \\
\hline África do Sul & GII & PIB real & JSE/FTSE TOP 40 \\
\hline 2010 & $51^{\circ}$ & $375.349 .442 .837,00$ & $28.639,40$ \\
\hline 2011 & $59^{\circ}$ & $416.596 .719 .622,00$ & $28.469,81$ \\
\hline 2012 & $54^{\circ}$ & $397.391 .258 .596,00$ & $34.975,50$ \\
\hline 2013 & $58^{\circ}$ & $366.057 .913 .367,00$ & $41.482,39$ \\
\hline 2014 & $53^{\circ}$ & $371.182 .724 .154,14$ & $43.746,86$ \\
\hline
\end{tabular}

Fonte: Elaborado pelos autores.

A utilização do coeficiente de correlação justifica-se pela possiblidade de captar a existência de alguma relação entre a variabilidade das variáveis aleatórias em análise. Uma vez que o objetivo da pesquisa consiste em observar o comportamento e a relação do mercado acionário com a evolução macroeconômica, tendo como base o desenvolvimento tecnológico nos países que constituem o BRICS, o cálculo do coeficiente de correlação 
permite determinar se essas variáveis estão ou não relacionadas de forma linear. Desse modo, para fins desse estudo, considera-se possível analisar a relação pretendida por meio da correlação estatística.

Utiliza-se como regra fundamental que o coeficiente de correlação " $\mathrm{r}$ " tenha um nível de confiança de $95,00 \%$ e um nível de significância de 5,00\%, ou seja, é estatisticamente significativo ao nível de p-valor $<0,05$. Além disso, também se considera que sua aceitação deve ter uma força de associação enquadrada como "muito forte", isto é, situada entre o intervalo de covariação $[ \pm 0,91 ; \pm 1,00]$. O Quadro 2 apresenta os intervalos de covariação e as respectivas forças de associação que norteiam a análise dos resultados.

Quadro 2 - Intervalos de covariação e força de associação

\begin{tabular}{|c|c|}
\hline Coeficiente de correlaçáo "r" de Pearson & Força de associaçáo \\
\hline $\pm 0,91- \pm 1,00$ & Muito forte \\
\hline $\pm 0,71- \pm 0,90$ & Alta \\
\hline $\pm 0,41- \pm 0,70$ & Moderada \\
\hline $\pm 0,21- \pm 0,40$ & Pequena, mas definida \\
\hline $\pm 0,01- \pm 0,20$ & Leve, quase imperceptível \\
\hline
\end{tabular}

Fonte: Adaptado de Hair Jr. et al. (2005).

O cálculo do coeficiente de correlação " $\mathrm{r}$ " se deu a fim de determinar se há uma relação coerente e sistemática entre as variáveis inovação (GII), desempenho do mercado acionário (índice das bolsas de valores) e desempenho da economia (PIB real). É importante compreender que, havendo tal relação, ela não é necessariamente causal, ou seja, não se pode inferir que uma variável causa a outra, uma vez que a correlaçáo não exprime uma relação de causa e efeito, tendo uma intepretação matemática. Assim, o entendimento de outros elementos contribuiu para uma melhor apreensão da relação existente entre essas variáveis, como a presença de relação, a natureza das relaçóes, a direção e a própria força de associação.

\section{RESULTADOS E DISCUSSÃO}

\subsection{Análise dos resultados para o Brasil}

Tendo como norte os parâmetros e as restriçôes descritos na metodologia, primeiramente analisa-se a correlação entre a variável de inovação GII com o Índice Ibovespa, em seguida, entre o Índice Ibovespa com o PIB real e, por último, entre o PIB real com a variável de inovação GII. A matriz de correlação entre essas variáveis é apresentada no Quadro 3. 
Quadro 3 - Matriz de correlação para o Brasil

\begin{tabular}{|l|c|c|c|}
\hline Variáveis & GII & PIB real & IBOVESPA \\
\hline GII & - & $-0,965726$ & 0,266427 \\
\hline PIB real & $-0,965726$ & - & $-0,369585$ \\
\hline IBOVESPA & 0,266427 & $-0,369585$ & - \\
\hline
\end{tabular}

Fonte: Elaboração própria.

No caso da primeira relação, ocorrida entre o GII e o Índice Ibovespa, verifica-se a existência de um coeficiente de correlação com direção positiva de 0,266427. Assim, é possível inferir que não há presença de relação linear coerente e sistemática entre as duas variáveis. A força de correlação é descrita como "pequena, mas definida" e a probabilidade de se conhecer o comportamento de uma variável não permite prever o comportamento da outra.

Observa-se que entre o Índice Ibovespa e o PIB real há um coeficiente de correlação de direção negativa de ordem $-0,369585$, indicando a não existência de presença de correlaçáo linear coerente e sistemática entre essas duas variáveis. Embora a força de correlação seja descrita como "pequena, mas definida", a probabilidade de se conhecer o comportamento de uma variável também não permite prever o comportamento da outra.

Levando-se em consideração os dados do PIB real e os do GII, a relação indica o oposto das anteriores. Nesse caso, constata-se a existência de presença de relação linear coerente e sistemática entre essas duas variáveis, com um coeficiente de correlação com direção negativa de -0,965726, o que indica uma força de correlação descrita como "muito forte". Assim, é possível inferir com uma probabilidade segura que, ao se conhecer o comportamento de uma variável é possível também se conhecer e prever o comportamento da outra.

Para o Brasil, os resultados encontrados indicam que apenas na relação entre o PIB real com o GII há presença de uma correlação linear coerente e sistemática entre essas duas variáveis. Logo, pode-se inferir que conhecer o comportamento de uma variável possibilita conhecer e prever o comportamento da outra. No entanto, como as demais relaçóes são insatisfatórias conforme os critérios adotados nesse estudo, rejeita-se a hipótese de pesquisa, pois não se identifica de modo coerente que variaçóes no Índice Ibovespa estariam refletindo variaçóes nos níveis de inovaçáo (GII) e, consequentemente, no desempenho macroeconômico (PIB real).

\subsection{Análise dos resultados para a Rússia}

Conforme os parâmetros e as restriçóes descritos na metodologia, primeiramente analisa-se a correlaçáo entre a variável de inovaçáo GII com a da bolsa de valores RTSI, em seguida, entre o índice da bolsa de valores RTSI com o PIB real e, por último, entre o PIB real com a variável de inovação GII. A matriz de correlação entre essas variáveis é apresentada no Quadro 4. 
Quadro 4 - Matriz de correlação para a Rússia

\begin{tabular}{|l|c|c|c|}
\hline Variáveis & GII & PIB real & RTSI \\
\hline GII & - & $-0,620155$ & 0,721825 \\
\hline PIB real & $-0,620155$ & - & $-0,688596$ \\
\hline RTSI & 0,721825 & $-0,688596$ & - \\
\hline
\end{tabular}

Fonte: Elaboração própria.

Na primeira relação, ocorrida entre o índice de inovação GII e o índice da bolsa de valores RTSI, o coeficiente de correlação encontrado tem direção positiva de 0,721825. Assim, é possível inferir que talvez exista presença de associação coerente e sistemática entre as duas variáveis, sustentado pela força de associação ser descrita como "alta". No entanto, essa relação é descartada pela desconformidade com os critérios estabelecidos para essa pesquisa, pois a probabilidade de se conhecer com exatidão o comportamento das variáveis não apresenta um grau de certeza estatisticamente significativo, ou seja, 95,00\% de confiança.

Com relação à segunda análise, realizada entre o índice da bolsa de valores RTSI com o PIB real, o coeficiente de correlação observado tem direção negativa de -0,688596, indicando que não há presença de associação coerente e sistemática entre essas duas variáveis. Embora a força de associação seja descrita como "moderada", a probabilidade de se conhecer e prever o comportamento de uma variável também não permite conhecer e prever o comportamento da outra.

Já com relação à terceira comparação, realizada levando-se em consideração o PIB real e o índice de inovação GII, observa-se a existência de um coeficiente de correlação de direção negativa de ordem -0,620155, indicando que não há presença de correlação linear coerente e sistemática entre essas duas variáveis. De forma similar à relação anterior, embora a força de correlação seja descrita como "moderada", a probabilidade de se conhecer e prever o comportamento de uma variável também não possibilita conhecer e prever o comportamento da outra.

Para a Rússia, os resultados encontrados sugerem que não há correlação ou aparente relação linear coerente e sistemática que possibilite conhecer e descrever o comportamento das variáveis de estudo. Embora o coeficiente de correlação entre o índice de inovação GII e o índice da bolsa de valores RTSI seja descrito como "alto", a probabilidade de se conhecer com exatidão o comportamento das variáveis não apresenta um grau de certeza estatisticamente significativo, ou seja, 95,00\% de confiança. Com isso, pode-se inferir que nenhuma das relaçóes atende aos critérios estabelecidos para essa pesquisa, rejeitando-se a hipótese de estudo. Logo, variaçóes no índice da bolsa de valores RTSI não estariam refletindo variaçóes nos níveis de inovação (GII) e, consequentemente, no desempenho macroeconômico (PIB real). 


\subsection{Análise dos resultados para a Índia}

Primeiramente analisa-se a correlação entre o GII com o índice da bolsa de valores S\&P BSE SENSEX, em seguida, entre o índice da bolsa de valores S\&P BSE SENSEX com o PIB real e, por último, entre o PIB real com o GII. A matriz de correlação entre essas variáveis é apresentada no Quadro 5.

Quadro 5 - Matriz de correlaçáo para a Índia

\begin{tabular}{|l|c|c|c|}
\hline Variáveis & GII & PIB real & S\&P BSE SENSEX \\
\hline GII & - & 0,974099 & 0,742121 \\
\hline PIB real & 0,974099 & - & 0,579136 \\
\hline S\&P BSE SENSEX & 0,742121 & 0,579136 & - \\
\hline
\end{tabular}

Fonte: Elaboração própria.

Na primeira relação, ocorrida entre o índice de inovação GII e o índice da bolsa de valores S\&P BSE SENSEX, o coeficiente de correlaçáo encontrado é de direção positiva de ordem 0,742121. É possível inferir que talvez exista presença de uma relaçấo linear coerente e sistemática entre essas duas variáveis, sustentado pela força de correlaçáo ser descrita como "alta". No entanto, tal relação é descartada pela desconformidade com os critérios estabelecidos para essa pesquisa, uma vez que a probabilidade de se conhecer com exatidáo o comportamento das variáveis não apresenta um grau de certeza estatisticamente significativo, ou seja, $95,00 \%$ de confiança.

$\mathrm{Na}$ análise realizada entre o índice da bolsa de valores S\&P BSE SENSEX com o PIB real, verifica-se a existência de um coeficiente de correlação de direção positiva de 0,579136 . Isso indica que não há presença de uma relação linear coerente e sistemática entre essas duas variáveis. Embora a força de correlação seja descrita como "moderada", a probabilidade de se conhecer e prever o comportamento de uma variável também náo possibilita conhecer e prever o comportamento da outra.

Na terceira comparação, realizada entre o PIB real e o índice de inovação GII, observase o oposto. Nesse caso, constata-se a existência de presença de relaçáo linear coerente e sistemática entre essas duas variáveis, com um coeficiente de correlaçẫo de direção positiva de 0,974099 , o que indica uma força de correlaçáo caracterizada como "muito forte". É possível inferir com uma probabilidade segura que, ao se conhecer o comportamento de uma variável é possível também conhecer e prever o comportamento da outra.

Com isso, os resultados para a Índia demonstram que apenas na relação entre o PIB real e o índice de inovação GII se observa a existência e a presença de correlação linear coerente e sistemática entre essas duas variáveis. Isso possibilita inferir que conhecer o comportamento de uma variável permite também conhecer e prever o comportamento da outra.

Embora a relação ocorrida entre o índice de inovação GII e o índice da bolsa de valores S\&P BSE SENSEX seja sido descrito como "alta", a probabilidade de se conhecer com exatidão o comportamento dessas variáveis não apresenta um grau de certeza estatisticamente 
significativo, ou seja, 95,00\% de confiança. Com isso, pode-se inferir que nenhuma das relações atende aos critérios estabelecidos para essa pesquisa, rejeitando-se, novamente, a hipótese de estudo, pois variaçóes no índice da bolsa de valores S\&P BSE SENSEX não estariam refletindo variações nos níveis de inovação (GII) e, consequentemente, no desempenho macroeconômico (PIB real).

\subsection{Análise dos resultados para a China}

Primeiramente, analisa-se a correlação entre as variáveis do índice global de inovação GII com o índice da bolsa de valores SSE Composite, logo em seguida entre o índice da bolsa de valores SEE Composite com o PIB real e, por último, entre o PIB real com o índice de inovação GII. A matriz de correlação entre essas variáveis é apresentada no Quadro 6.

Quadro 6 - Matriz de correlação para a China

\begin{tabular}{|l|c|c|c|}
\hline Variáveis & GII & PIB real & SEE COMPOSITE \\
\hline GII & - & $-0,651544$ & 0,019773 \\
\hline PIB real & $-0,651544$ & - & 0,143263 \\
\hline SEE COMPOSITE & 0,019773 & 0,143263 & - \\
\hline
\end{tabular}

Fonte: Elaboração própria.

É possível observar que, na primeira relação, ocorrida entre o índice de inovação GII e o índice da bolsa de valores SSE Composite, há um coeficiente de correlação com direção positiva de 0,019773. Pode-se inferir que não há presença de correlação coerente e sistemática entre essas variáveis, uma vez que a força de correlação encontrada é descrita como "leve, quase imperceptível". Por essa razáo, a probabilidade de se conhecer e prever o comportamento de uma variável náo permite conhecer e prever o comportamento da outra.

Com relação à segunda análise, realizada entre o índice da bolsa de valores SSE Composite com o PIB real, o coeficiente de correlação observado tem direção positiva de 0,143263 . Portanto, é possível inferir que não há presença de associação coerente e sistemática entre essas duas variáveis e que a força de correlação encontrada é descrita como "leve, quase imperceptível". Assim, a probabilidade de se conhecer e prever o comportamento de uma variável não possibilita conhecer e prever o comportamento da outra.

Já em relação à terceira comparação, realizada levando-se em consideração o PIB real e o índice de inovação GII, observa-se que há um coeficiente de correlação de direção negativa de $-0,651544$. Isso indica que não existe presença de uma relaçáo linear coerente e sistemática entre essas duas variáveis. Embora a força de correlação encontrada seja descrita como "moderada", a probabilidade de se conhecer e prever o comportamento de uma variável não permite conhecer e prever o comportamento da outra.

Os resultados para a China demonstram uma completa inexistência de relação coerente e sistemática entre as variáveis analisadas. É possível inferir de modo seguro que nenhuma das relaçóes atende aos critérios estabelecidos para essa pesquisa, rejeitando-se a hipótese de estudo, pois variaçóes nos índices da bolsa de valores SEE Composite não 
estariam refletindo, de forma coerente e sistemática, as variações nos níveis de inovação (GII) e, consequentemente, no desempenho macroeconômico (PIB real) do país.

\subsection{Análise dos resultados para a África do Sul}

Para a África do Sul, primeiramente é analisada a correlação entre a variável índice global de inovação GII e o índice da bolsa de valores JSE/FTSE TOP40, posteriormente analisa-se a correlação entre o índice da bolsa de valores JSE/FTSE TOP40 com o PIB real e, em seguida, entre o PIB real com o índice de inovação GII. A matriz de correlação é apresentada no Quadro 7.

Quadro 7 - Matriz de correlação para a África do Sul

\begin{tabular}{|l|c|c|c|}
\hline Variáveis & GII & PIB real & JSE/FTSE TOP40 \\
\hline GII & - & 0,429552 & 0,013530 \\
\hline PIB real & 0,429552 & - & $-0,649517$ \\
\hline JSE/FTSE TOP40 & 0,013530 & $-0,649517$ & - \\
\hline
\end{tabular}

Fonte: Elaboração própria.

$\mathrm{Na}$ relação entre o índice de inovação GII e o índice da bolsa de valores JSE/FTSE TOP 40, o coeficiente de correlação é de 0,013530 , com direção positiva. É possível inferir que não há presença de correlação coerente e sistemática entre essas duas variáveis e que a força de correlação é descrita como "leve, quase imperceptível”. Dessa forma, a probabilidade de se conhecer e prever o comportamento de uma variável não permitirá conhecer e prever o comportamento da outra.

$\mathrm{Na}$ comparação entre o índice da bolsa de valores JSE/FTSE TOP40 com o PIB real, observa-se um coeficiente de correlação com direção negativa de -0,649517, indicando que não há presença de uma relação linear coerente e sistemática entre essas duas variáveis. Embora a força de associação encontrada seja descrita como "moderada", a probabilidade de se conhecer e prever o comportamento de uma variável não permitirá conhecer e prever o comportamento da outra.

$\mathrm{Na}$ comparação entre o PIB real e o índice de inovação GII, observa-se um coeficiente de correlação com direçáo positiva de 0,429552 , indicando que não há presença de correlação linear coerente e sistemática entre essas duas variáveis. Embora a força de correlação encontrada seja descrita como "moderada", a probabilidade de se conhecer e prever o comportamento de uma variável, também não permitirá conhecer e prever o comportamento da outra.

Para a África do Sul, os resultados demonstram uma completa inexistência de relação coerente e sistemática entre as variáveis analisadas. Em vista disso, é possível inferir de forma segura que nenhuma das relações atende aos critérios estabelecidos para essa pesquisa, rejeitando-se a hipótese de estudo, pois variaçóes no índice da bolsa de valores JSE/FTSE TOP40 não estariam refletindo de modo coerente e sistemático variações nos níveis de inovação (GII) e no desempenho macroeconômico (PIB real). 


\subsection{Relaçáa entre inovaçáo, mercado acionário e crescimento econômico para os países do BRICS}

Os países do BRICS apresentam um significativo potencial de crescimento econômico, que pode ser atribuído às vantagens que apresentam em termos de riqueza de recursos naturais e de terra, mão de obra farta e barata, e alta densidade de investimento estrangeiro direto (IED) (BINGWEN; HUIBO, 2010). No entanto, em economias do conhecimento, a inovação abarca um potencial amplamente mais importante enquanto fator de crescimento e desenvolvimento econômico de uma nação do que fatores como terra, capital físico ou mão de obra (BINGWEN; HUIBO, 2010). Com efeito, uma gestáo eficaz da inovaçáo é a chave para o sucesso corporativo, a capacidade tecnológica e o desenvolvimento econômico sustentável (BINGWEN; HUIBO, 2010). O Quadro 8 apresenta uma síntese do panorama atual da inovação nos países membros do BRICS.

Quadro 8 - Panorama atual da inovação nos países do BRICS

\begin{tabular}{|c|l|}
\hline País & \multicolumn{1}{c|}{ Características inovativas } \\
\hline Brasil & $\begin{array}{l}\text { Considera-se o sistema científico qualificado, sendo as atividades de pesquisa e } \\
\text { desenvolvimento (P\&D) significativamente desiguais, logrando sucessos nas áreas } \\
\text { aeroespacial, energia, mineração, metalurgia e agronegócios. Além disso, destaca-se a } \\
\text { fragilização e a desarticulaçáo de alguns sistemas de inovação nos anos 1990. }\end{array}$ \\
\hline Rússia & $\begin{array}{l}\text { Os destaques ficam a cargo da qualidade da educaçâo superior, de um sistema } \\
\text { científico particularmente dedicado às atividades espaciais e relacionadas à defesa, } \\
\text { além dos gastos em P\&D se expandindo. }\end{array}$ \\
\hline Índia & $\begin{array}{l}\text { Há um sistema científico em expansão com ampla qualidade, P\&D industrial } \\
\text { relativamente modesta, recursos humanos de alta qualidade e capacitaçóes produtivas } \\
\text { particularmente em tecnologias da informação. }\end{array}$ \\
\hline China & $\begin{array}{l}\text { Nesse país, há um esforço considerável em mobilizar o sistema nacional de educação } \\
\text { e de inovação, com acúmulo de capacitaçóes produtivas e inovativas e atividades de } \\
\text { P\&D crescendo a taxas elevadas com ênfase nos setores hi-tech. }\end{array}$ \\
\hline África do & $\begin{array}{l}\text { Observa-se um crescente esforço em educação superior, atividades inovativas e de } \\
\text { P\&D relativamente modestas assim como uma infraestrutura científica limitada. } \\
\text { No entanto, há destaque para as capacitaçôes produtivas realizadas nas atividades de } \\
\text { extraçáo mineral. }\end{array}$ \\
\hline
\end{tabular}

Fonte: Lastres et al. (2007).

Os países membros do BRICS apresentam capacidade industrial significativa e altos níveis de autossuficiência, exceto no domínio dos bens de consumo e tecnologias avançadas (KAHN, 2015). Além disso, possuem avançadas competências médicas, científicas e técnicas e contribuem para o estoque global de conhecimento (KAHN, 2015).

Nesse contexto, considera-se essencial construir um sistema que absorva as tecnologias estrangeiras avançadas levando as empresas nacionais a investirem em inovação (BINGWEN; HUIBO, 2010). Em nível nacional, o regime de concorrência deve incentivar o processo de aprendizado nas empresas domésticas, absorvendo novos conhecimentos e realizando inovaçōes (BINGWEN; HUIBO, 2010). Em nível internacional, a concorrência deve motivar as empresas estrangeiras a trazerem as tecnologias mais avançadas para o mercado doméstico (BINGWEN; HUIBO, 2010). Isso se traduz, evidentemente, no fortalecimento 
do mercado acionário, pois torna as empresas mais competitivas e aumenta a confiança do investidor. Ademais, também cria incentivos para a canalização de investimentos estrangeiros diretos, tornando os países do BRICS mais competitivos no mercado global. Via de regra, pode-se esperar pelo fortalecimento da atividade econômica, melhorando os níveis de produtividade e o desempenho econômico desses países.

Em um sistema de economia de mercado, as empresas constituem parte essencial da economia, sendo a inovaçáo tecnológica representa, principalmente, por progresso econômico (BINGWEN; HUIBO, 2010). Isso implica que as empresas devem ser o principal veículo de investimento em $\mathrm{P} \& \mathrm{D}$, inovação tecnológica e aplicação dos resultados da inovação (BINGWEN; HUIBO, 2010). Novamente, enfatiza-se que a ênfase nos processos inovativos das empresas poderá traduzir-se no fortalecimento do mercado acionário e também no desempenho econômico desses países. Defende-se a ideia de que esses investimentos sejam realizados em forma de estratégias que visem coadunar conhecimento desenvolvido em universidades, com o potencial e sua efetiva aplicação no setor produtivo, as empresas.

\section{CONSIDERAÇÓES FINAIS}

O estudo teve por objetivo analisar o comportamento e a relação do mercado acionário com a evoluçáo macroeconômica, tendo como base o desenvolvimento tecnológico, nos países que constituem o BRICS. Foi testada a hipótese de que uma diminuiçáo nos preços das açôes pode estar refletindo más notícias em relação ao progresso tecnológico e ao crescimento econômico de longo prazo.

Com base nos resultados apresentados, não foi possível identificar, de forma coerente e sistemática, uma relação entre a inovação tecnológica, o crescimento econômico e o desempenho do mercado de capitais, que fosse capaz de descrever o comportamento dessas variáveis para o Brasil, a Rússia, a Índia, a China e a África do Sul. A hipótese de estudo foi rejeitada, permitindo concluir que o desempenho do mercado de capitais náo pode servir de indicador econômico para os países do BRICS, uma vez que não há evidências de que seu desempenho esteja relacionado com o desempenho da economia real e com o desempenho da inovação tecnológica.

Os resultados encontrados corroboram com outras pesquisas que não encontraram evidências efetivas entre o desempenho do mercado de açóes com a inovação tecnológica e o crescimento econômico, tais como: (ARESTIS; DEMETRIADES; LUINTEL, 2001; BECK, 2003; HOOK, 2004; ZHU, ASH; POLLIN, 2004; BECK; LEVINE, 2004; DRITSAKI; DRITSAKI-BARGIOTA, 2005; HONDROYIANNIS; LOLOS; PAPAPETROU, 2005; BEM-NACEUR; GHAZOUANI, 2007; PILO, 2012; KUOSMANEN; VATAJA, 2013; FLORACKIS, et al., 2014; AHMED; MMOLAINYANE, 2014; ODHIAMBO, 2014).

Os estudos, a priori, refletem as evidências e as percepçóes para o cenário econômico intrínseco com relação ao espaço temporal desenvolvido nas referidas pesquisas, as variáveis analisadas e as metodologias utilizadas. Para tanto, ressalta-se que resultados diferentes podem ser encontrados caso modifique-se a abrangência dos países analisados. Como sugestão para estudos futuros, sugere-se replicar essa abordagem para um grupo de países 
desenvolvidos, como Estados Unidos, Canadá, Reino Unido, França, Itália, Alemanha e Japão, e realizar comparaçóes com os resultados aqui apresentados com o intuito de observar se graus de maturidade nos setores analisados (inovaçáo, mercado de capitais e desempenho do PIB real) interferem na forma como as variáveis de estudo se relacionam.

Considera-se como principal limitação dessa pesquisa a delimitação da variável utilizada para representar a inovação, o GII, uma vez que se utilizou a nota de posicionamento dos países do BRICS como referência para o quesito inovação tecnológica. Dessa forma, em uma análise empregando-se outras variáveis características da inovação, é possível que resultados diferentes dos desse estudo sejam encontrados.

A principal contribuição dessa pesquisa está na possibilidade de refletir sobre temas que se mostram cada vez mais pertinentes para a conjuntura econômica global. Uma vez que é crescente a representatividade dos países do BRICS no concernente à atração de investimento e produção mundiais, analisar a relação entre inovação tecnológica, desempenho do mercado acionário e desempenho econômico, mostra-se importante na medida em que permite definir açóes estratégicas, nesse âmbito, com o intuito de aumentar a competitividade desses países no cenário internacional.

Além disso, esse estudo, ao relacionar inovação, mercado acionário e crescimento econômico, visa fomentar e fortalecer as pesquisas sobre inovação nos países membros do BRICS. Isso em razão da importância que esse elemento, a inovação, apresenta para o progresso econômico atual das naçóes, principalmente as emergentes. Logo, analisar o impacto dessa variável sobre o desempenho do mercado acionário, haja vista a necessidade de inovar intrínseca à sobrevivência das empresas em um ambiente competitivo, e os reflexos disso sobre a performance econômica dos países, que está condicionada, via de regra, a um bom funcionamento do setor produtivo, consiste em uma forma de potencializar os benefícios da inovação para um crescimento econômico sustentado e para o alcance do desenvolvimento econômico.

\section{REFERÊNCIAS}

AHMED, A. D.; MMOLAINYANE, K. K. Financial integration, capital market development and economic performance: Empirical evidence from Botswana. Economic Modelling, 42, p. 1-14, 2014.

ARESTIS, P. P.; DEMETRIADES, P.; LUINTEL, K. B. Financial Development and Economic Growth: The Role of Stock Markets. Journal of Money, Credit and Banking, 33(1), p. 16-4, 2001.

BECK, T. Stock Markets, Banks and Economic Development: Theory and Evidence.

European Investment Bank Papers, 08, p. 36-54, 2003.

BECK, T.; LEVINE, R. Stock Markets, Banks and Growth: Panel Evidence. Journal of Banking \& Finance, 28(3), p. 423-442, 2004. 
BEN-NACEUR, S.; GHAZOUANI, S. Stock Markets, Banks and Economic Growth: Empirical Evidence from MENA Region. Research in International Business and Finance, 21, p. 297-315, 2007.

BINGWEN, Z.; HUIBO, Z. Estudo comparativo sobre sistemas nacionais de inovação nas economias BRIC. Revista Tempo do Mundo - RTM, v.2, n.2. p. 119-147, ago. 2010 .

CARMO, C. A. do. BRICS: de estratégia do mercado financeiro à construção de uma estratégia de política internacional. Carta Internacional (Publicação da Associaçáo Brasileira de Relaçóes Internacionais), v. 6, n.2, p.03-15, jul./dez. 2011.

DRITSAKI, C.; DRITSAKI-BARGIOTA, D. M. The Causal Relationship between Stock, Credit Market and Economic Development: An Empirical Evidence from Greece. Economic Change and Restructuring, 38, p. 113-127, 2005.

FASANYA, I. O.; ONAKOYA, A. B. O.; OFOEGBU, D. I. Capital Market Development: A Spur to Economic Growth in Nigeria. Acta Universitatis Danubius, 9(5), p. 222-234, 2013.

THE GLOBAL INNOVATION INDEX (GII). The Global Innovation Index.

Disponível em: <http://globalinnovationindex.org/content.aspx?page=GII-Home>. Acesso em: 10/06/2015.

GOLDSMITH, R. W. Financial Structure and Development. New Haven, 1969.

HAIR JR., J. F., BLACK, W. C.; BABIN, B. J., ANDERSON, R. E.; TATHAM, R. L. Análise multivariada de dados. 5. ed. Porto Alegre: Bookman, 2005.

HICKS, J. A. Theory of Economic History. Oxford: Claredon Press, 1969.

HONDROYIANNIS, G.; LOLOS, S.; PAPAPETROU, E. Financial Markets and Economic Growth in Greece, 1986-1999. Journal of International Financial Markets, Institutions and Money, 15, p. 173-188, 2005.

HOOK, L. S. Banks, Stock Markets and Economic Performance: Panel Data Evidence from Developing Economies. Labuan Bulletin of International Business and Finance, 2(1), 9-29, 2004.

KAHN, M. A Cooperação dos BRICS na Ciência, Tecnologia e Inovação: Retórica e Realidades. Contexto Internacional, Rio de Janeiro, v.37, n.1, p.185-213, jan./abr. 2015.

KUZNETS, S. O crescimento econômico do pós-guerra. Rio de Janeiro: Fundo de cultura, 1966. 
LASTRES, H. M. M.; CASSIOLATO, J.; MATOS, M.; SZAPIRO, M.; ZUCOLOTO, G.; KOELLER, P. Estudo comparativo dos sistemas nacionais de inovação no Brasil, Rússia, Índia, China e África do Sul (BRICS). Disponível em: <http://www.redesist. ie.ufrj.br/brics/Projeto\%20BRICS.pdf>. Aceosso em: 07 jul. 2017.

LEVINE, R.; ZERVOS, S. Stock Markets, Banks and Economic Growth. American Economic Review, 98, p. 537-558, 1998.

LI, H. Issues existing in the capital market in Jilin Province and solutions. Journal of Politics and Law, 5(1), p. 196-200, 2012.

LUCAS, R. J. On the Mecanics of Economic Development. Journal of Monetary Economics, 22, p. 3-42, 1988.

LUCAS, R. J. Expectations and the Neutrality of Money. Journal of Economic Theory, 4 (2), p. 103-124, 1972.

MADDISON, A. A. Comparison of Levels of GDP Per Capita in Developed and Developing Countries, 1700-1980. The Journal of Economic History, 43(1), p. 27-41, 1983.

MANKIW, N. G. Macroeconomia. Rio de Janeiro, LTC, 2011.

MITCHENER, K. J.; OHNUKI, M.. Institutions, Competition, and Capital Market Integration in Japan. The Journal of Economic History, 69(1), p. 138-171, 2009.

MODIGLIANI, F.; MILLER, M. H. The Cost of Capital, Corporation Finance and the Theory of Investment. The American Economic Review, 48(3), p. 261-297, 1958.

MOHD, S. A. Indian capital market review: issues, dimensions and performance analysis. UTMS Journal of Economic, (2), p. 181-191, 2012.

NGAREA, E.; NYAMONGOB, E. M.; MISATI, R. N. Stock market development and economic growth in Africa. Journal of Economics and Business, 74, p. 24-39, 2014.

ODHIAMBO, N. M. Financial Depth, Savings and Economic Growth in Kenya: A Dynamic Causal Linkage. Economic Modelling, 25, p. 704-713, 2008.

ODHIAMBO, N. M. Financial systems and economic growth in South Africa: a dynamic complementarity test. International Review of Applied Economics, 28(1), p. 83-101, 2014.

PILO, M. T. M. Comportamento Bolsista e Desempenho Macroeconômico: Estudo de Caso em seis Países Africanos. Ed. Instituto Superior de Economia e Gestão da Universidade Técnica de Lisboa, Lisboa, 2012. 
PORTER, M. E. Competiçáo: estratégias competitivas essenciais. Rio de Janeiro: Campus, 1999.

ROMER, P. M. Increasing Returns and Long-Run Growth. Journal of Political Economy, The University of Chicago Press, 1986.

ROMER, P. M. Endogenous technological change. Journal of Political Economy, 98, p. 571-602, 1990.

SACHS, J. D.; LARRAIN, F. B. Macroeconomia: em uma economia global. São Paulo: Pearson Makron Books, 2000.

SAYAD, J.; SILBER, S. D. Comércio Internacional. In: PINHO, D. B.;

VASCONCELLOS, M. A. S. de (orgs.). Manual de economia. 5 ed. São Paulo: Saraiva, 2005.

SCHUMPETER, J. A. Teoria do Desenvolvimento Econômico: uma investigaçáo sobre lucros, capital, crédito, juro e o ciclo econômico. São Paulo: Abril Cultural, 1951.

SHAW, E. S. Financial Deepening in Economic Development. New York: Oxford University Press, 1973.

SHEN, C. H.; LEE, C. C. Same Financial Development Yet Different Economic GrowthWhy? Journal of Money, Credit and Banking, 38(7), p. 1907-1944, 2006.

SOLOW, R. A contribution to the theory of economic growth. Quarterly Journal of Economics, 70, p. 65-94, 1956.

TIGRE, P. B. Gestáo da inovação: a economia da tecnologia no Brasil. Rio de Janeiro: Elsevier, 2006.

ZHANG, J.; WANG, L.; WANG, S. Financial Development and Economic Growth: Recent Evidence from China. Journal of Comparative Economics, 40, p. 393-412, 2012.

ZHU, A.; ASH, A.; POLLIN, R. Stock Market Liquidity and Economic Growth: A Critical Appraisal of the Levine/Zervos Model. International Review of Applied Economics, 18(1), p. 63- 71, 2004. 